\title{
Gold-catalyzed cyclization of allenyl acetal derivatives
}

\author{
Dhananjayan Vasu, Samir Kundlik Pawar and Rai-Shung Liu*
}

\section{Full Research Paper}

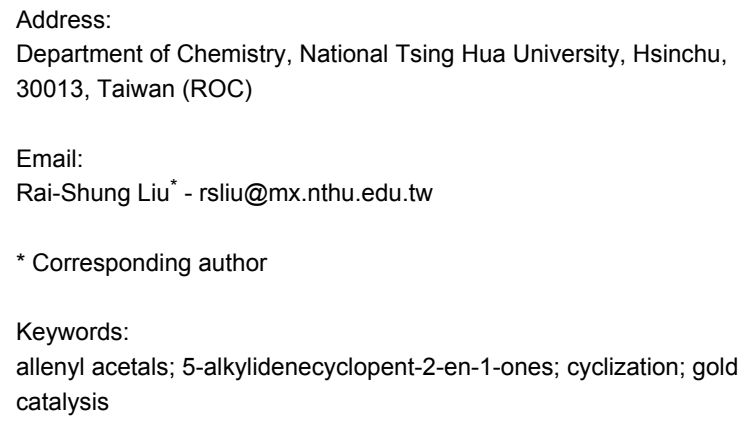

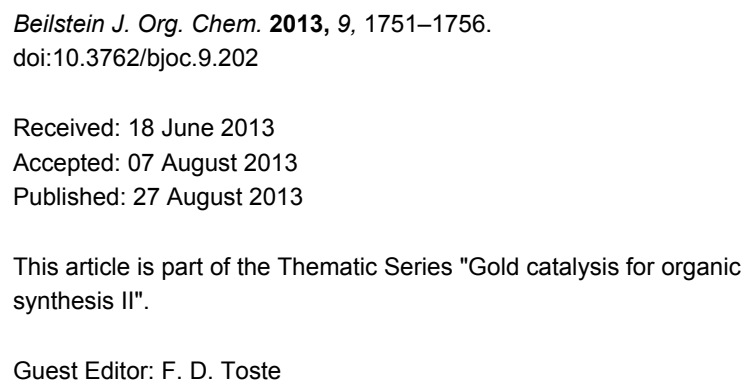

(C) 2013 Vasu et al; licensee Beilstein-Institut.

License and terms: see end of document.

\begin{abstract}
The gold-catalyzed transformation of allenyl acetals into 5-alkylidenecyclopent-2-en-1-ones is described. The outcome of our deuterium labeling experiments supports a 1,4-hydride shift of the resulting allyl cationic intermediates because a complete deuterium transfer is observed. We tested the reaction on various acetal substrates bearing a propargyl acetate, giving 4-methoxy-5alkylidenecyclopent-2-en-1-ones 4 via a degradation of the acetate group at the allyl cation intermediate.
\end{abstract}

\section{Introduction}

Gold-catalyzed cyclization/cycloaddition reactions [1-5] are useful synthetic methods to construct complicated carbo- and oxacyclic frameworks. Such cascade reactions have been well studied on various difunctionalized molecules including oxoalkynes [6-13], oxoallenes [14], oxoalkenes [15] and allenyl acetals [16-18]. In this cascade sequence, two new rings and three chemical bonds are generated in a one-pot procedure. We previously reported gold-catalyzed reactions of allenyl acetals with suitable dipolarophiles such as 1,3-diones to chemoselectively produce the cycloaddition product 2 [17] (Scheme 1). Similar reactions with nitrones stereoselectively delivered distinct formal cycloadducts 3 [18]. We postulate that compounds 2 arise from the attack of 1,3-diones at initially gener- ated allyl cation intermediates I. In the case of electrophilic nitrones, allyl cations I release a proton to form reactive 1-methoxyfulvenes II to achieve a [3 + 2]-nitrone cycloaddition. The versatility of cationic intermediates $\mathbf{I}$ encourages us to understand their behavior in the absence of a dipolarophile. This work reports gold-catalyzed intramolecular cyclizations of these allenyl acetals [19].

\section{Results and Discussion}

We first tested the intramolecular cyclizations of allenyl acetal 1a with $\mathrm{PPh}_{3} \mathrm{AuCl} / \mathrm{AgSbF}_{6}(5 \mathrm{~mol} \%)$, which was shown to be an active catalyst in the two cascade reactions, as depicted in Scheme $1[17,18]$. As shown in Table 1, the treatment of com- 


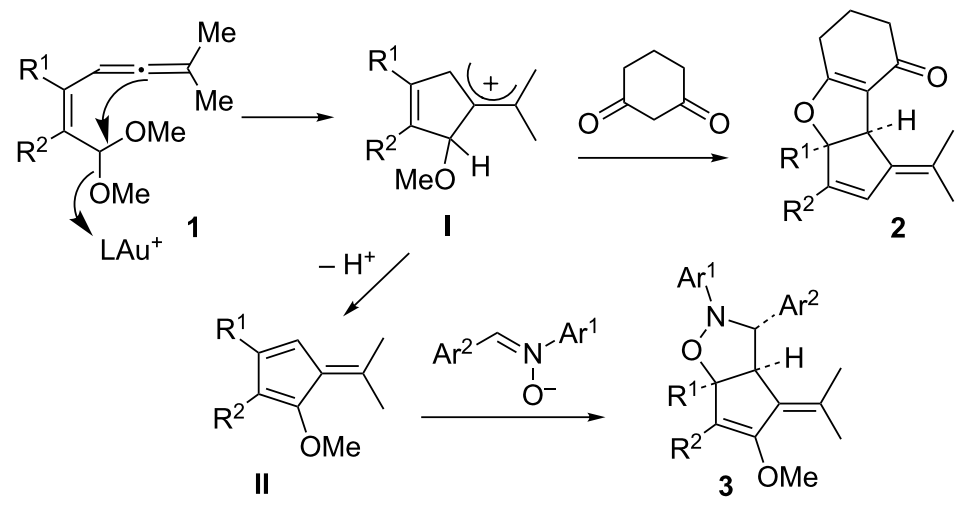

Scheme 1: Reported cascade reactions on allenyl acetals.

pound 1a with this gold catalyst (5 mol \%) in dichloromethane (DCM, $28^{\circ} \mathrm{C}, 0.5 \mathrm{~h}$ ) afforded 5-isopropylidenecyclopent-2-en1 -one derivative $4 \mathrm{a}$ in $65 \%$ yield (Table 1 , entry 1 ). With a change of the counter anion as in $\mathrm{PPh}_{3} \mathrm{AuCl} / \mathrm{AgOTf}$, the product yield increased to $89 \%$ (Table 1, entry 2). $\mathrm{PPh}_{3} \mathrm{AuCl} /$ $\mathrm{AgNTf}_{2}$ was also active to give the same product in $83 \%$ yield (Table 1, entry 3). Under the same conditions, AgOTf alone gave the desired $4 \mathbf{a}$ in $48 \%$ yield (Table 1, entry 4 ). $\mathrm{AuCl}_{3}$ and $\mathrm{PtCl}_{2}$ enabled a complete consumption of the starting material 1a, but the yields of compound $4 \mathbf{a}$ were $51 \%$ and $30 \%$, respectively (Table 1, entries 5 and 6).

\begin{tabular}{|c|c|c|c|c|}
\hline \multirow[b]{2}{*}{ Entry $^{a}$} & $\mathrm{Me}_{\mathrm{Me}}^{\mathrm{Me}}$ & \multicolumn{2}{|c|}{$\begin{array}{c}\begin{array}{c}\text { catalyst } \\
(5 \mathrm{~mol} \%)\end{array} \\
\underset{\mathrm{DCM}, 25^{\circ} \mathrm{C}}{\longrightarrow}\end{array}$} & a 0 \\
\hline & Catalyst & & Time (h) & Yield $(\%)^{\mathrm{b}}$ \\
\hline 1 & \multicolumn{2}{|c|}{$\mathrm{PPh}_{3} \mathrm{AuCl} / \mathrm{AgSbF}_{6}$} & 0.5 & 65 \\
\hline 2 & \multicolumn{2}{|c|}{$\mathrm{PPh}_{3} \mathrm{AuCl} / \mathrm{AgOTf}$} & 0.5 & 89 \\
\hline 3 & \multicolumn{2}{|c|}{$\mathrm{PPh}_{3} \mathrm{AuCl} / \mathrm{AgNTf}_{2}$} & 0.5 & 83 \\
\hline 4 & \multicolumn{2}{|c|}{ AgOTf } & 2.0 & 48 \\
\hline 5 & \multicolumn{2}{|l|}{$\mathrm{AuCl}_{3} / \mathrm{CO}$} & 1.5 & 51 \\
\hline 6 & \multicolumn{2}{|l|}{$\mathrm{PtCl}_{2} / \mathrm{CO}$} & 1.5 & 30 \\
\hline
\end{tabular}

$\mathrm{a}[\mathrm{a}]=0.1 \mathrm{M} .{ }^{\mathrm{b}}$ Isolated yields

Table 2 shows the substrate scope including additional allenyl acetals $\mathbf{1 b}-\mathbf{1 h}$. The reactions were catalyzed by $\mathrm{PPh}_{3} \mathrm{AuCl} /$ $\operatorname{AgNTf}_{2}(5 \mathrm{~mol} \%)$ in DCM. As shown in entries $1-3$, this cyclization was applicable to allenyl acetals $\mathbf{1 b}-\mathbf{1 d}$ bearing a cyclopentyl bridge. The resulting products $\mathbf{4 b}-\mathbf{4 d}$ were produced with satisfactory yields $(68-82 \%)$. We also tested the reaction on acyclic allenyl acetal 1 e $(E / Z=3: 1)$, and afforded the desired product $4 \mathrm{e}$ in $52 \%$ yield according to initial $E$-configured 1e. The structure of compound $4 \mathbf{e}$ was determined by ${ }^{1} \mathrm{H}$ NMR NOE spectra. The reaction was still operable with 1f, bearing a 1,2-disubsituted allene, giving the desired $\mathbf{4 f}$ in moderate yield (49\%). Its $E$-configuration was determined by NOE measurements, and assignable to other products including $\mathbf{4 g}$ and $\mathbf{4 h}$. The reaction worked well with substrates bearing a different trisubstituted allenes, giving the desired cyclopentenone $\mathbf{4 g}$ and $\mathbf{4 h}$ in $82-83 \%$ yields.

The preceding cyclization is mechanistically interesting because it involves a cleavage of the $\mathrm{C}-\mathrm{H}$ bond of the acetal group. We prepared $\mathbf{d}_{\mathbf{1}} \mathbf{- 1 a}$ bearing a deuterium ( $>98 \%$, Scheme 2 , reaction 1) at its acetal group. The resulting product $\mathbf{d}_{\mathbf{1}} \mathbf{- 4 a}$ has almost one full deuterium $(\mathrm{X}=0.98 \mathrm{D})$ at one of the methylene protons according to DEPT ${ }^{13} \mathrm{C}$ NMR analysis. In the presence of added $\mathrm{D}_{2} \mathrm{O}$, undeuterated 1a gave the product without deuterium content (Scheme 2, reaction 2). The results of these labeling experiments reveal a 1,4-hydrogen shift [20-22] in the $\mathbf{d}_{\mathbf{1}}-\mathbf{1} \mathbf{a} \rightarrow \mathbf{d}_{\mathbf{1}} \mathbf{- 4 a}$ transformation.

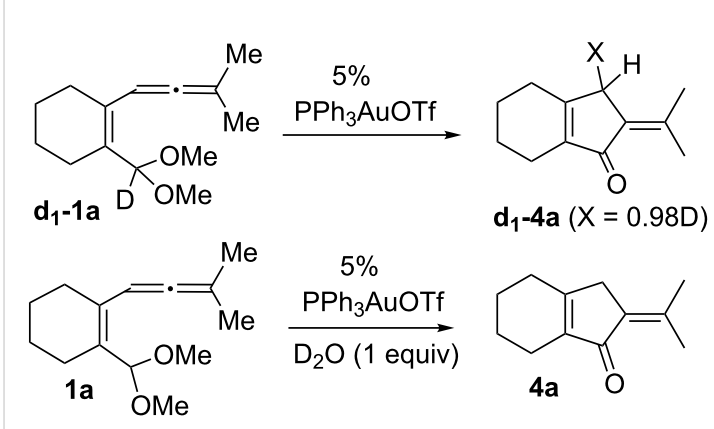

Scheme 2: Gold-catalyzed cyclization of deuterated $\mathbf{d}_{\mathbf{1}}-\mathbf{1 a}$. 
Table 2: Gold-catalyzed cyclization of allenyl acetals.

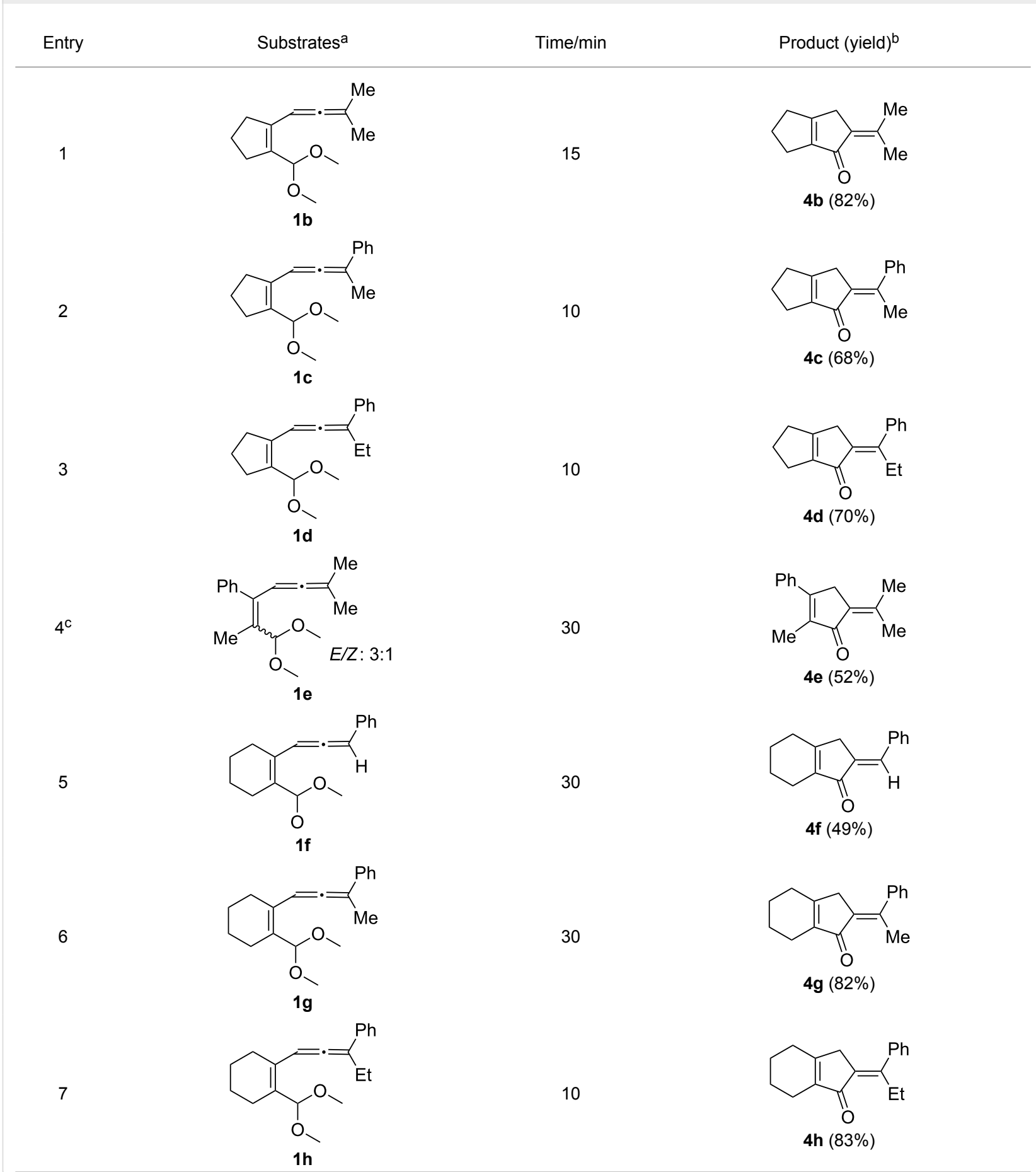

a5 mol \% AuCIPPh $/$ AgOTf, [1] $=0.1 \mathrm{M}, 25{ }^{\circ} \mathrm{C}, \mathrm{DCM}$. b/solated yield. ${ }^{\mathrm{c}} 10 \mathrm{~mol} \%$ of gold catalyst.

Scheme 3 shows a plausible mechanism to rationalize the transformation of the allenyl acetal 1e into the observed cyclopentenone 4e. The deuterium labeling experiment of the $\mathbf{d}_{\mathbf{1}} \mathbf{- 1} \mathbf{a} \rightarrow \mathbf{d}_{\mathbf{1}} \mathbf{- 4 a}$ transformation (Scheme 2, reaction 1) indicates that one methylene proton of $\mathbf{4 a}$ is derived from the original acetal group. Accordingly, we postulate a 1,4-hydride shift $[21,22]$ for the intermediate transformation $\mathbf{B} \rightarrow \mathbf{C}$. We excluded an alternative route involving the protonation of the fulvene intermediate $\mathbf{D}$ because this route would water as a proton source. The formation of the fulvene intermediate $\mathbf{D}$ from allyl 


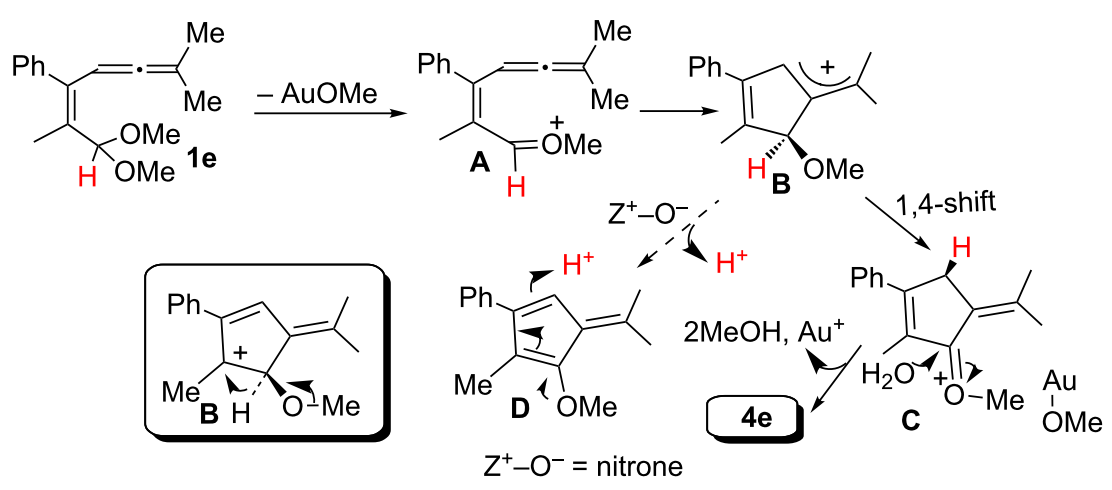

Scheme 3: A plausible reaction mechanism.

cation $\mathbf{B}$ is assisted by a weak base like nitrone [18]. We envisage that a 1,2-hydrogen shift for the allyl cation $\mathbf{B}$ fails to explain a complete deuterium transfer for the $\mathbf{d}_{\mathbf{1}} \mathbf{- 1} \mathbf{a} \rightarrow \mathbf{d}_{\mathbf{1}}-\mathbf{4 a}$ transformation because its resulting cyclopent-3-en-1-one derivative became isomerized to the final product $\mathbf{4 a}$ with a loss of deuterium content.

We also prepared the substrate 5a bearing a propargyl acetate moiety because this functionality can be transferred to the allenyl acetate $\mathbf{5}$ '' by a gold catalyst $[23,24]$. As shown in Scheme 4 , the treatment of species 5a with $\mathrm{PPh}_{3} \mathrm{AuOTf}$ $(5 \mathrm{~mol} \%)$ in dichloromethane $\left(28{ }^{\circ} \mathrm{C}, 5 \mathrm{~min}\right)$ gave 4-methoxy5 -isopropylidenecyclopent-2-en-1-one $\mathbf{6 a}$ in $76 \%$ yield. The structure of compound 6a was determined by an X-ray diffraction study (crystallographic data are provided in Supporting Information File 1). Formation of this product is postulated to arise from the attack of the methoxy anion at the acetyl group of the corresponding allyl cation $\mathbf{E}$, a process not involving a 1,4hydride shift. This alternative pathway highlights the diversified mechanism of such oxidative cyclizations.

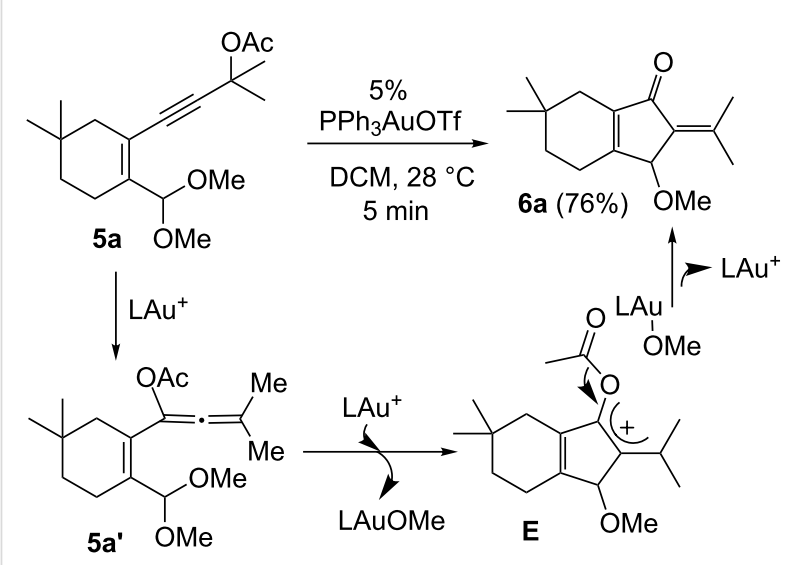

Scheme 4: The reaction of propargyl acetate $\mathbf{5 a}$.
We prepared the additional substrates $\mathbf{5 b}-\mathbf{5 g}$ bearing an acetate group to examine the scope of the reaction, results are shown in Table 3. This gold-catalyzed cyclization was applicable to compound $\mathbf{5 b}$ bearing a cyclopentyl bridge, giving the desired $\mathbf{6 b}$ in $96 \%$ yield. The reaction worked also with $\mathbf{5 c}$ and $\mathbf{5 d}$ bearing a cyclohexyl bridge, delivering the desired products $\mathbf{6 c}$ and $\mathbf{6 d}$ in $78 \%$ and $72 \%$ yields, respectively (Table 3 , entries 2 and 3 ). We tested the reaction with the benzenoid substrates $\mathbf{5 e}-\mathbf{5 g}$, giving the corresponding enones $\mathbf{6 e - 6 g}$ in $63-78 \%$ yields.

\section{Conclusion}

In summary, we report a gold-catalyzed transformation of allenyl acetals 1 into 5-alkylidenecyclopent-2-en-1-ones 4. Our deuterium labeling experiments support a 1,4-hydride shift for the resulting allyl cation because of a complete deuterium transfer. This observation excludes the pathway involving the protonation of a 1-methoxyfulvene species. We tested the reactions of acetal substrates 5 bearing a propargyl acetate to afford 4-methoxy-5-alkylidenecyclopent-2-en-1-ones $\mathbf{6}$. The formation mechanism involves a degradation of the acetate group at the corresponding allyl cation.

\section{Experimental \\ General procedure for the gold-catalyzed carbocyclization}

General procedure for the the gold(I)-catalyzed carbocyclization of vinylallenyl acetal: A two-necked flask was charged with chloro(triphenylphosphine)gold(I) (11.1 mg, $0.022 \mathrm{mmol})$ and silver triflate $(5.8 \mathrm{mg}, 0.022 \mathrm{mmol})$, and to this mixture $\mathrm{CH}_{2} \mathrm{Cl}_{2}(2.0 \mathrm{~mL})$ was added. The resulting solution was stirred at room temperature for $10 \mathrm{~min}$. To this mixture a solution of vinylallenyl acetal $1 \mathrm{a}(100 \mathrm{mg}, 0.45 \mathrm{mmol})$ in $\mathrm{CH}_{2} \mathrm{Cl}_{2}(2.5 \mathrm{~mL})$ was added dropwise, and the mixture was kept stirring at $25^{\circ} \mathrm{C}$ for $30 \mathrm{~min}$ before it was filtered over a short silica bed. The solvent was evaporated under reduced pressure. The crude product was eluted through a short silica 
Table 3: Gold-catalyzed carbocyclization of propargylic esters.

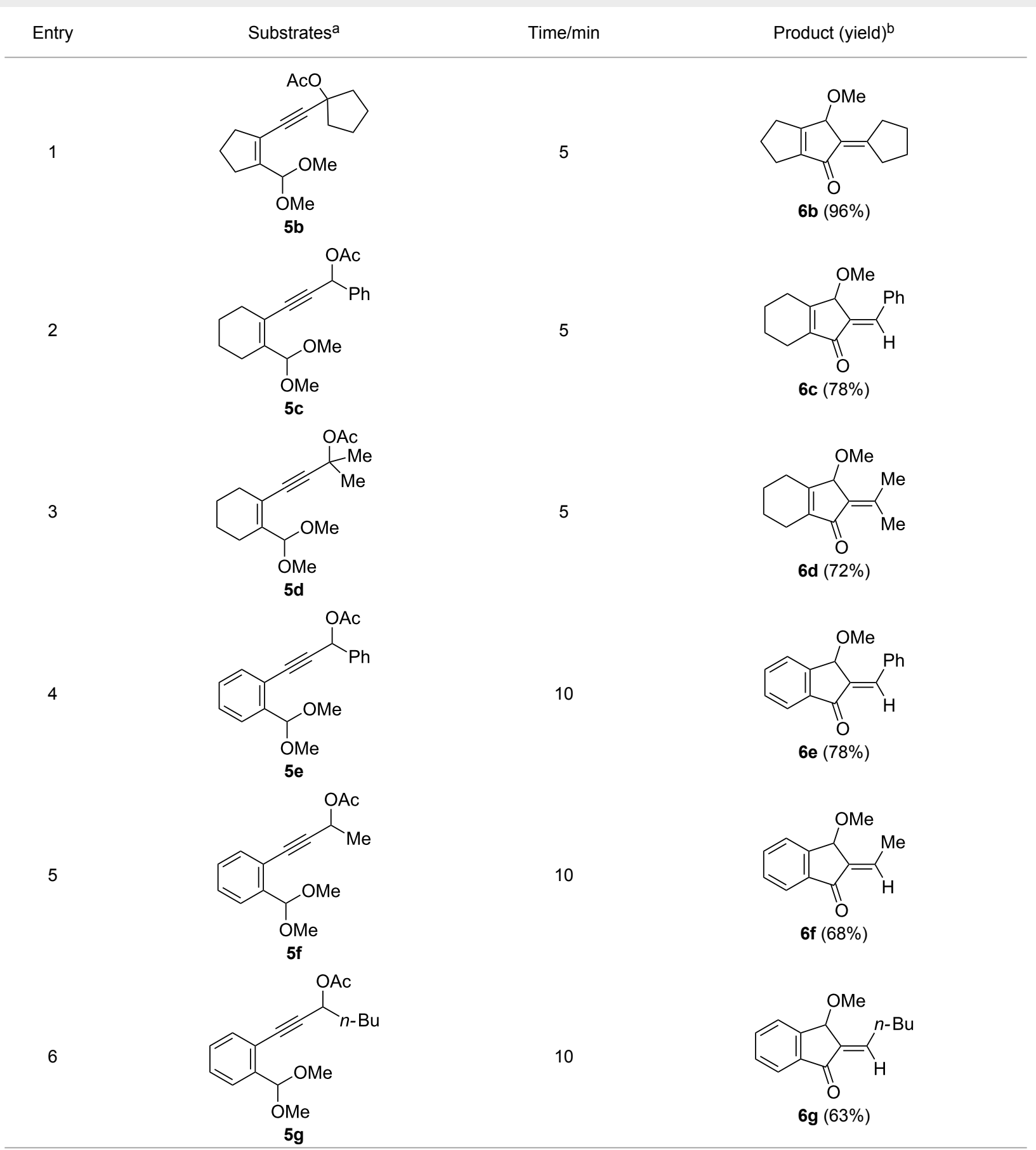

a5 mol \% $\mathrm{AuClPPh}_{3} / \mathrm{AgOTf},[5]=0.1 \mathrm{M}, 25^{\circ} \mathrm{C}, \mathrm{DCM}$. ${ }^{\text {b }}$ Isolated yield .

column ( $3 \%$ ethyl acetate in hexane) to afford the desired ketone 4 a (70.6 mg, $0.40 \mathrm{mmol}, 89 \%)$ as a pale yellow oil.

General procedure for the gold(I)-catalyzed carbocyclization of propargylic ester acetals: Chloro(triphenylphosphine $)$ gold(I) $(8.0 \mathrm{mg}, 0.016 \mathrm{mmol})$ and silver triflate $(4.2 \mathrm{mg}$,
$0.016 \mathrm{mmol}$ ) were added to a dried Schlenk tube under an $\mathrm{N}_{2}$ atmosphere, and freshly distilled $\mathrm{CH}_{2} \mathrm{Cl}_{2}(1.0 \mathrm{~mL})$ was introduced by a syringe. The resulting mixture was stirred at room temperature for 10 minutes before the addition of propargylic ester acetal $5 \mathbf{a}(100 \mathrm{mg}, 0.32 \mathrm{mmol})$ in $\mathrm{CH}_{2} \mathrm{Cl}_{2}(2.2 \mathrm{~mL})$. The reaction mixture was stirred for additional 5 minutes at $25^{\circ} \mathrm{C}$. 
After the completion of reaction, the brown suspension was filtered through a short bed of silica gel. The solvent was removed under reduced pressure. The crude product was purified by flash chromatography to afford the desired ketone $\mathbf{6 a}$ (58 $\mathrm{mg}, 0.25 \mathrm{mmol}, 76 \%$ ) as a dark yellow oil.

\section{Supporting Information}

\section{Supporting Information File 1}

Experimental details.

[http://www.beilstein-journals.org/bjoc/content/

supplementary/1860-5397-9-202-S1.pdf]

\section{Acknowledgements}

We thank the National Science Council, Taiwan, for financial support of this work.

\section{References}

1. Patil, N. T.; Yamamoto, Y. Chem. Rev. 2008, 108, 3395. doi:10.1021/cr050041j

2. Sohel, S. M. A.; Liu, R.-S. Chem. Soc. Rev. 2009, 38, 2269. doi:10.1039/b807499m

3. López, F.; Mascareñas, J. L. Beilstein J. Org. Chem. 2011, 7, 1075. doi:10.3762/bjoc.7.124

4. Aubert, C.; Fensterbank, L.; Garcia, P.; Malacria, M.; Simonneau, A. Chem. Rev. 2011, 111, 1954. doi:10.1021/cr100376w

5. Rudolph, M.; Hashmi, A. S. K. Chem. Soc. Rev. 2012, 41, 2448. doi:10.1039/c1cs15279c

6. Teng, T.-M.; Das, A.; Huple, D. B.; Liu, R.-S. J. Am. Chem. Soc. 2010, 132, 12565. doi:10.1021/ja106493h

7. Liu, F.; Qian, D.; Li, L.; Zhao, X.; Zhang, J. Angew. Chem., Int. Ed. 2010, 49, 6669. doi:10.1002/anie.201003136

8. Liu, F.; Yu, Y.; Zhang, J. Angew. Chem., Int. Ed. 2009, 48, 5505. doi:10.1002/anie.200901299

9. Asao, N.; Kasahara, T.; Yamamoto, Y. Angew. Chem., Int. Ed. 2003, 42, 3504. doi:10.1002/anie.200351390

10. Asao, N.; Aikawa, H.; Yamamoto, Y. J. Am. Chem. Soc. 2004, 126, 7458. doi:10.1021/ja0477367

11. Hsu, Y.-C.; Ting, C.-M.; Liu, R.-S. J. Am. Chem. Soc. 2009, 131, 2090. doi:10.1021/ja809560c

12. Hashmi, A. S. K.; Littmann, A. Chem.-Asian J. 2012, 7, 1435. doi:10.1002/asia.201200046

13. Teng, T.-M.; Liu, R.-S. J. Am. Chem. Soc. 2010, 132, 9298. doi:10.1021/ja1043837

14. Lin, C.-C.; Teng, T.-M.; Tsai, C.-C.; Liao, H.-Y.; Liu, R.-S. J. Am. Chem. Soc. 2008, 130, 16417. doi:10.1021/ja806415t

15. Lin, C.-C.; Teng, T.-M.; Odedra, A.; Liu, R.-S. J. Am. Chem. Soc. 2007, 129, 3798. doi:10.1021/ja069171f

16. Bhunia, S.; Liu, R.-S. J. Am. Chem. Soc. 2008, 130, 16488. doi:10.1021/ja807384a

17. Teng, T.-M.; Lin, M.-S.; Vasu, D.; Bhunia, S.; Liu, T.-A.; Liu, R.-S. Chem.-Eur. J. 2010, 16, 4744. doi:10.1002/chem.201000041

18. Vasu, D.; Liu, R.-S. Chem.-Eur. J. 2012, 18, 13638. doi:10.1002/chem.201201777
19. Nakamura, I.; Mizushima, Y.; Gridnev, I. D.; Yamamoto, Y. J. Am. Chem. Soc. 2005, 127, 9844. doi:10.1021/ja051114j

20. Busch-Petersen, J.; Corey, E. J. Org. Lett. 2000, 2, 1641. doi:10.1021/ol005964

21. Shintani, R.; Okamoto, K.; Hayashi, T. J. Am. Chem. Soc. 2005, 127, 2872. doi:10.1021/ja042582g

22. Bolte, B.; Odabachian, Y.; Gagosz, F. J. Am. Chem. Soc. 2010, 132, 7294. doi:10.1021/ja1020469

23. Zhang, L. J. Am. Chem. Soc. 2005, 127, 16804. doi:10.1021/ja056419c

24. Marion, N.; Díez-González, S.; de Frémont, P.; Noble, A. R.;

Nolan, S. P. Angew. Chem., Int. Ed. 2006, 45, 3647.

doi:10.1002/anie.200600571

\section{License and Terms}

This is an Open Access article under the terms of the Creative Commons Attribution License

(http://creativecommons.org/licenses/by/2.0), which permits unrestricted use, distribution, and reproduction in any medium, provided the original work is properly cited.

The license is subject to the Beilstein Journal of Organic Chemistry terms and conditions:

(http://www.beilstein-journals.org/bjoc)

The definitive version of this article is the electronic one which can be found at: doi:10.3762/bjoc. 9.202 